\title{
Alice in Wonderland: uma tradução literária em imagens por Suzy Lee
}

\author{
Alice in Wonderland: a literary translation \\ in images by Suzy Lee
}

\section{Elizabeth da Penha Cardoso}

\section{Luis Carlos Barroso de Sousa Girão}

Pontifícia Universidade Católica de São Paulo - PUC-SP - São Paulo - São Paulo - Brasil

Resumo: Em 2015, um dos maiores clássicos da literatura infanto-juvenil moderna, Alice in Wonderland, completou 150 anos de lançamento. A obra-prima do controverso Lewis Carroll já foi traduzida e adaptada nos mais diversos meios de expressão artística. Em 2002, despontando na contemporânea literatura para crianças e jovens, Suzy Lee publicou sua tradução intersemiótica de Alice em livro-imagem. Análoga à ideia de Carroll referente a "um sonho dentro de um sonho", Lee segue em sua publicação a ideia de "um livro dentro de um livro", tornando ainda mais clara sua fonte de inspiração para a sua criação/recriação/adaptação. Objetivando realizar uma breve análise das obras literárias de Carroll e Lee, propomos um diálogo com os estudos de Roman Jakobson e os escritos do artista Julio Plaza no que se refere à tradução intersígnica, entre signos do código verbal para o código visual, para as versões de Alice in Wonderland aqui enunciadas. Sugerimos ainda uma aproximação com as ideias de Robert Stam sobre a adaptação literária, no caso da presente proposta, do livro ilustrado para o livro-imagem - narrativa composta por palavras para uma narrativa construída por imagens.

Palavras-chave: Adaptação. Literatura Infantil. Tradução Intersemiótica.

Abstract: In 2015, one of the biggest classics from the modern children's literature, Alice in Wonderland, completed 150 years of release. The masterpiece of the controversial Lewis Carroll has been translated and adapted into many artistic expression's medias. In 2002, emerging in contemporary literature for children, Suzy Lee published her intersemiotic translation of Alice in picture-book (a publication made with pictorial narratives) to the original picturebook from the British author. In harmony with Carroll's idea regarding to "a dream within a dream", Lee follows in her publication the idea of "a book within a book", making even more clear her source of inspiration to her creation/recreation/adaptation. Aiming to conduct a brief analysis for the literary works of Carroll and Lee, we're proposing a dialogue with studies from Roman Jakobson and the writings of the artist Julio Plaza regarding to an intersign translation, between signs from a verbal code to a visual code, related to the versions of Alice in Wonderland here stated. We're also suggesting an approach to Robert Stam's ideas regarding to literary adaptation, in this proposal's case, from a picturebook to a picture-book - from a narrative composed by words to a narrative build by pictures.

Keywords: Children's Literature. Intersemiotic Translation. 


\section{Introdução}

Em julho de 1865, o britânico Charles Lutwidge Dodgson, conhecido pelo pseudônimo Lewis Carroll, publicou a primeira edição daquele que viria a se tornar um dos cânones da literatura mundial e infantil: Alice's Adventures in Wonderland - também referido pelo título Alice in Wonderland. A história da garotinha que caiu pelo buraco do Coelho Branco é resultado de uma narrativa oral elaborada pelo tímido matemático às filhas do reverendo Henry Liddell durante um passeio de barco em Oxford. Por ter o mesmo nome que a protagonista, a caçula Alice Liddell pediu ao narrador que colocasse em palavras escritas aquela história de fantasia, o que levou Carroll a escrever sua primeira grande obra literária.

As releituras de Alice para os mais distintos campos de expressão artística são notáveis, além das inúmeras reedições em livro, aqui destacamos a clássica animação pelos estúdios de Walt Disney em 1951, e a excêntrica adaptação cinematográfica dirigida por Tim Burton, em 2010, também pela Disney. No entanto, trazemos ao centro da presente discussão uma tradução literária em imagens, uma adaptação narrativa sem palavras realizada por Suzy Lee.

Publicado em 2002 pela Corraini Edizioni, na Itália, o livro-imagem - publicação composta por narrativas pictóricas - foi a primeira obra literária da artista plástica sul-coreana, resultado do seu mestrado em Book Arts, pela Camberwell College of Arts, em Londres, Inglaterra. O nome de Lee é um dos mais citados por especialistas no panorama da literatura infantil e juvenil contemporânea, uma vez que ela produz livros sem utilizar signos verbais para emitir significação, para contar uma estória.

$\mathrm{Na}$ tentativa de realizar o exercício de reflexão aqui proposto, apropriamo-nos do conceito de tradução intersemiótica cunhado pelo linguista russo Roman Jakobson (1974), em seus escritos sobre as funções da tradução literária, o qual inspirou o extenso trabalho desenvolvido pelo artista plástico espanhol, radicado no Brasil, Julio Plaza (2003). Ressaltamos que, para tal diálogo sobre uma tradução intersígnica, partiremos do pensamento em signos, legado do filósofo norte-americano Charles Sanders Peirce, porém não nos aprofundaremos em uma discussão sobre a semiótica peirceana.

$\mathrm{Na}$ primeira parte deste artigo, daremos enfoque a alguns aspectos presentes na obra de Carroll que foram traduzidos de signos verbais para signos visuais na obra de Lee, trazendo à luz algumas referências de que a book artist sul-coreana faz uso em seu processo de criação.

Em seguida, sugerimos uma reflexão acerca do trabalho de recriação feito por Suzy Lee a partir do trabalho de Lewis Carroll. Para tal reflexão, partiremos das considerações do crítico literário e teórico cinematográfico norte-americano Robert Stam (2000), no que se refere à adaptação fílmica, e do pesquisador brasileiro Marcel Alvaro de Amorim (2013) - este último em eco aos escritos do primeiro - no referente à adaptação como uma tradução intercultural, entre culturas.

Nesse segundo momento de análise em nossa discussão, seguimos de perto o argumento de Amorim e substituímos seu termo "adaptação fílmica" por "adaptação literária", apropriando-nos de sua lógica em benefício da análise. Conforme argumentamos, a tradução em imagens de Lee, em determinado momento de sua obra, torna-se recriação antropofágica (Haroldo de Campos, 2013), resultando em uma narrativa distinta da original, criada por Carroll.

\section{Tradução intersemiótica}

Quando se fala em semiose e na relação triádica dos signos - signo, objeto e interpretante -, a referência ao legado semiótico deixado por C. S. Peirce é imediata, uma vez que o filósofo e matemático dedicou parte considerável de sua vida a estudos sobre o assunto. O pensamento de Peirce ecoa na fala de Roman Jakobson, estruturalista russo que se apropriou da semiótica da linha peirceana para refletir sobre as qualidades literárias presentes na Linguística e na Comunicação.

Em um de seus ensaios teóricos sobre o trânsito de signos entre estas duas áreas do conhecimento, Jakobson se apóia nos escritos peirceanos para 
afirmar que a "linguagem deve ser estudada em toda a variedade de suas funções" (1974, p. 122). E a função poética dessa linguagem, tão defendida pelo crítico literário russo, deve ser compreendida como a troca de uma mensagem a partir de um remetente para um destinatário. Essa mensagem, carregada de potencial expressivo, caracteriza tal função da linguagem.

Jakobson afirma que tal mensagem poética possui uma capacidade informacional que independe das variantes diretamente ligadas às demais funções da linguagem. É justamente com a função poética da linguagem em mente que o estruturalista desenvolve uma discussão sobre aspectos linguísticos referentes à tradução.

Sobre este tema, Jakobson afirma que "o significado de um signo linguístico não é mais que sua tradução por um outro signo que the pode ser substituído, especialmente um signo no qual ele se ache desenvolvido de modo mais completo" (1974, p. 64). A partir dessa ótica, o crítico discorre acerca da falta que incita à complementaridade característica do signo linguístico, que o levará a cunhar o termo tradução inter-semiótica.

Jakobson escreve (1974, p. 65): "A tradução inter-semiótica ou transmutação consiste na interpretação dos signos verbais por meio de signos não verbais", ou seja, por signos visuais, sonoros, ou quaisquer outros signos distintos do verbal. No entanto, o pensamento do estruturalista parte sempre de um signo verbal para um outro signo, que o substitua e/ou complemente. Tal linha de pensamento se encontra refletida de forma mais abrangente nos escritos do artista espanhol Julio Plaza - um dos principais nomes que desenvolveu estudos sobre a tradução intersemiótica no Brasil, após ser radicado no País.

Em um período no qual artistas plásticos e poetas se dedicavam à linha de criatividade concretista, Plaza produziu muitos trabalhos envolvendo os mais diversos meios de expressão artística - poesias visuais, telas poéticas, dispositivos sonoros que evocassem o verbal e o visual. Seu aprofundado estudo sobre esta mescla, esta mistura de signos e sentidos culminou em seu livro Tradução
Intersemiótica, publicado pela Editora Perspectiva, em 2003, ano de sua morte.

Neste ensaio teórico, após desenvolver um raciocínio sobre a tradução entre signos como um intercurso de sentidos - olho, tato, acústico -, Plaza afirma (2003, p. 71):

Na tradução intersemiótica como transcriação de formas o que se visa é penetrar pelas entranhas dos diferentes signos, buscando iluminar suas relações estruturais, pois são essas relações que mais interessam quando se trata de focalizar os procedimentos que regem a tradução. Traduzir criativamente é, sobretudo, interagir estruturas que visam à transformação de formas.

Esta transformação de formas nos leva à primeira análise aqui proposta, sobre a tradução de um signo verbal para um signo visual, em acordo com a proposta de Jakobson. No entanto, Suzy Lee não utilizou apenas os escritos de Lewis Carroll para criar sua Alice. A book artist sul-coreana se apropriou de outros meios, outros signos, colocando estruturas para interagir, ecoando a proposta de Plaza.

\subsection{Carroll para Lee}

Em 2000, logo que chegou em Londres, Suzy Lee visitou uma exposição sobre Lewis Carroll na British Library. Ela teve acesso a manuscritos e ilustrações originais, além de cartas e diversos livros que estavam à mostra. Após essa visita, a artista sulcoreana retomou Alice in Wonderland como uma leitora adulta. Nesse processo, Lee pesquisou sobre alguns trabalhos publicados sobre Alice e foi inspirada pela sequência de fotos Alice's Mirror - trabalho de Duane Michals, revelado originalmente em 1974 -, bem como pela adaptação surreal para o cinema produzida pelo diretor tcheco Jan Svankmajer em 1988, intitulada Neco z Alenky.

Além disso, o mestrado em Book Arts permitiu que a artista pensasse no livro como um meio de arte. A ideia de que os elementos físicos do livro poderiam fazer parte de uma narrativa foi sendo desenvolvida ao longo de seus estudos, antes mesmo de publicar suas próprias obras, quando ainda ilustrava para outros autores. 
Ao produzir o livro-imagem Alice in Wonderland, Lee se apropriou das ideias de Carroll para a construção de sua própria Alice - como bem tornou público ao imprimir na folha de rosto de sua obra o seguinte: "Inspirado em Alice in Wonderland de Lewis Carroll"1. No entanto, a book artist transmutou alguns elementos que seguem a narrativa da obra original até certo ponto da história.

Enquanto a Alice de Carroll é uma garotinha britânica que, ao ouvir uma história lida por sua irmã mais velha, cai no sono ao pé de uma árvore, a Alice de Lee é uma garotinha oriental que aparece, em uma página dupla com a página esquerda totalmente escura, sentada em uma cadeira posicionada no centro do que parece ser um palco de teatro (Figura 1). A garotinha oriental é o recorte de uma fotografia, sobreposta a uma série de outras imagens referenciais utilizadas por Lee.

A Alice de Carroll sonha estar perseguindo um Coelho Branco, que segura um relógio preso ao bolso de um colete e afirma constantemente estar atrasado.
Maravilhas. Já a Alice de Lee se sobressalta ao notar a presença curiosa de um Coelho Branco, que, diferente da Alice em fotografia recortada, é o recorte de uma ilustração de carvão em papel branco.

Enquanto cai no palco inferior ao que estava anteriormente, Alice vai se transformando, de fotografia para ilustração em carvão, entrando no mesmo mundo imaginário do Coelho Branco. E aqui já podemos notar algumas das transformações nas formas realizadas por Lee. O Coelho Branco de Lee não é parecido com o Coelho Branco de Carroll - a ilustração traja um manto branco, mostrando um olhar temeroso para Alice.

Durante sua perseguição ao Coelho Branco, Alice, tanto em Carroll quanto em Lee, vê-se passando por situações nonsenses de mudança de tamanho, interagindo com outros ambientes e personagens imaginários, sempre com um ar de estranheza. A diferença entre as duas histórias é que a narrativa desenvolvida por Carroll está em signos verbais, em alguns momentos ilustrada em signos visuais por Sir John Tenniel, enquanto a narrativa de

Figura 1 - Alice aparece no palco, em recorte de fotografia

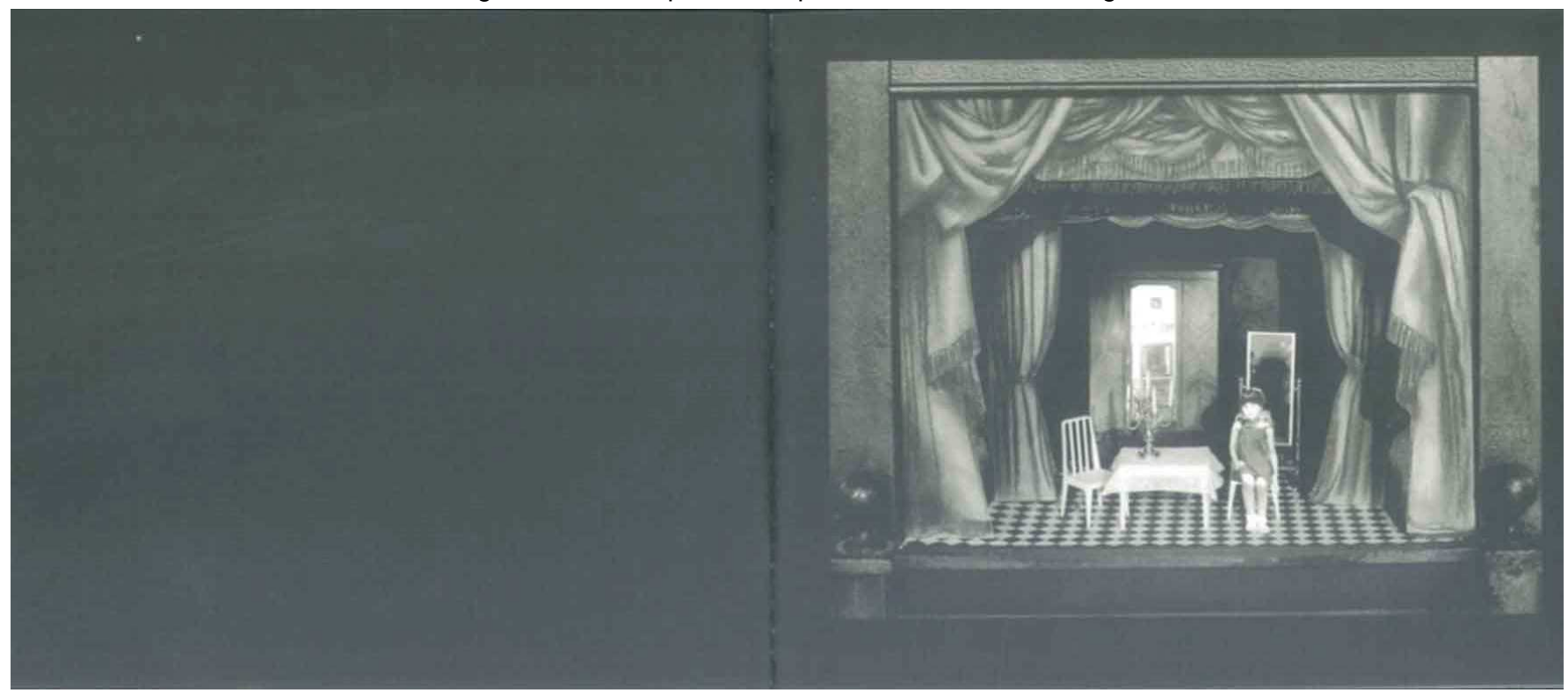

Fonte: Página dupla reproduzida de Lee (2002)

A garotinha britânica cai na toca desse coelho e segue caindo durante um longo tempo, até alcançar o fundo, onde ela começa a viver aventuras no País das

\footnotetext{
1 Tradução nossa para: "Inspired by Lewis Carroll's Alice in Wonderland".
}

Lee é produzida por uma sequência de signos visuais sem o uso de signos verbais. A ação da narrativa se 
dá pela leitura das imagens sequenciais, feita pela passagem de páginas duplas - característica dos livros-imagem.

Para sua narrativa, Suzy Lee se apropriou de algumas obras de arte que remetem o mundo imaginário, espaço onde sua protagonista está inserida. Ecoando as ideias de Julio Plaza, ela se apropria de signos visuais para transcriar sua estória de Alice dentro de um mundo repleto de sobreposições. Para melhor significar tal ambientação de sobreposição, a artista sul-coreana utiliza reproduções de telas como $A$ Flagelação de Cristo (1458-60), de Piero della Francesca; As Meninas (1656), de Diego de Velázquez (Figura 2); The Oculus in the Camera degli Sposi (1473), de Andrea Mantegna; Personal Values (1951-52), de René Magritte; e Apolo e Dáfne (1470-80), de Antonio del Pollaiuolo.

Ainda em um contexto situado no mundo imaginário, Suzy Lee não apenas transcriou parte da obra de Lewis Carroll, como também se apropriou daquilo que é apontado como leitmotif tanto em Alice in Wonderland quanto em Through the Looking-Glass, and What Alice Found There (1871) - conhecido pelo título Through the Looking-Glass -, que narra o de "sonho dentro de um sonho" e "espelho dentro de um espelho" para suas histórias vividas por Alice, Lee apoiou-se no princípio do "livro dentro do livro", chamando atenção para o objeto livro como elemento fundamental para o desenrolar da sua história contada em imagens.

A característica metaficcional de "livro dentro do livro" dialoga com a técnica primeiramente observada pelo autor francês André Gide, de "história dentro da história", que a ela se referiu como mise en abymeem texto de 1893, sobre a escrita do romance $L a$ tentative amoureuse. $\mathrm{O}$ termo diz respeito à narrativa estruturada "em abismo", como as bonecas russas, matrioskas, uma dentro da outra. O procedimento está presente na literatura - desde Quixote (1605), de Cervantes, e Tristram Shandy (1759), de Laurence Sterne, a Ulysses (1922), de Joyce, e Rayuela (1963), de Cortázar -, no teatro - Hamlet (1603), de Shakespeare; Sei personaggi in cerca d'autor (1921), de Luigi Pirandello -, no cinema - La nuit américaine (1973), de François Truffaut; Todo sobre mi madre (1999), de Almodóvar; 81/2 (1963), de Federico Fellini - e nas artes plásticas - O casal Arnolfini (1434), de Jan van Eyck, e o já

Figura 2 - Alice e o Coelho Branco se misturam à obra de Velázquez

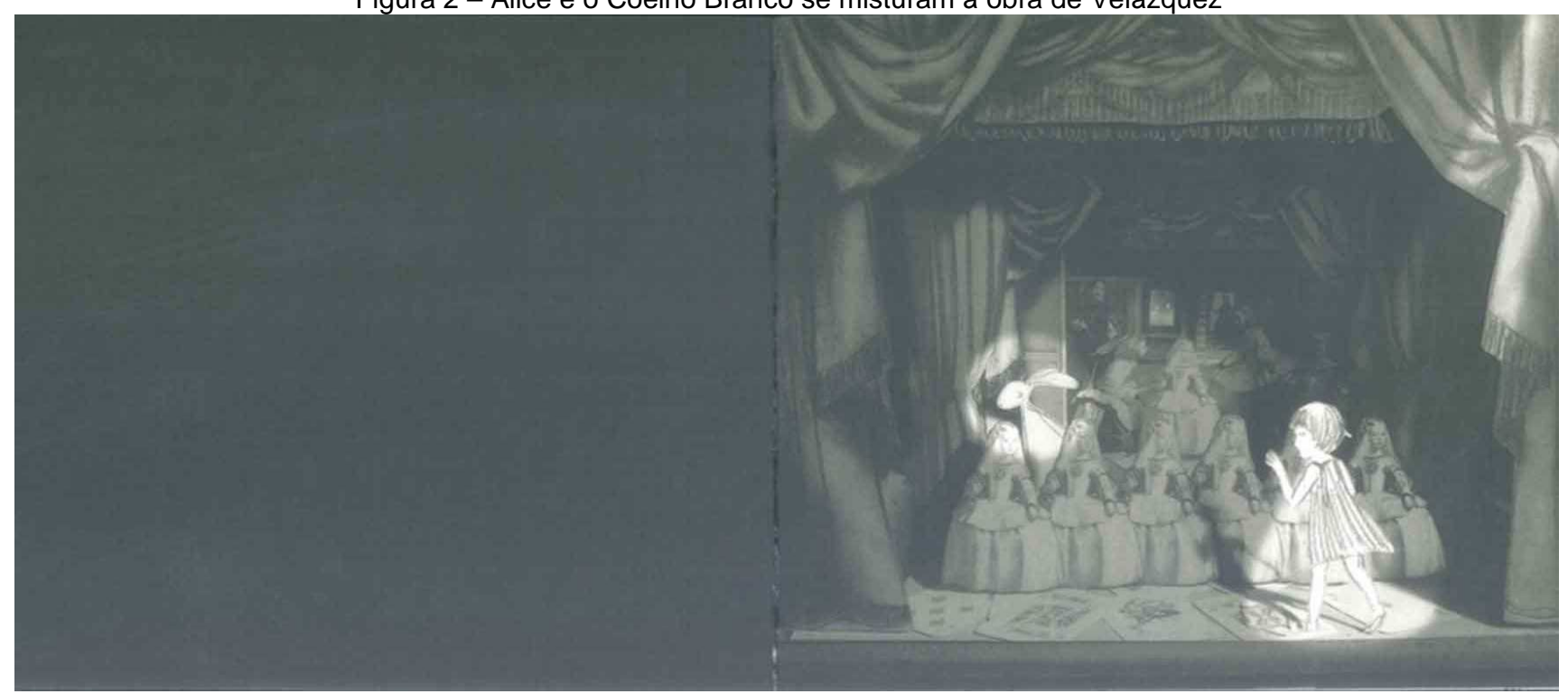

Fonte: Pánina dunla renrndı̇ida de I ẹ (วกก)

retorno de Alice ao País das Maravilhas ao entrar no espelho que fica em cima da lareira da sua sala de leitura. Ao passo que Carroll baseava-se nos princípios mencionado As Meninas, de Velázquez.

O crítico literário francês Lucien Dällenbach, em um de seus estudos sobre o trabalho de Gide, destaca 
quatro características básicas de tal recurso: ele é capaz de fazer a obra voltar-se sobre si mesma; objetiva ressaltar a inteligibilidade e a estrutura formal da obra; revela a realidade estrutural e sua denominação está associada a um procedimento emblemático, com relação à obra (DÄLLENBACH, 1991 , p. 16-17). Outro aspecto implicado na mise en abyme é sua capacidade de tornar o invisível visível, de revelar ângulos até então escondidos, ou não evidentes.

Essa característica específica se faz presente ao final do livro-imagem de Lee, quando Alice se despede da plateia que assistia à peça encenada por ela e pelo Coelho Branco, e o leitor se depara com um zoom out que ocorre no passar das páginas (Figura 3). Além de expor o caráter metaficcional de sua tradução literária em imagens - com a aparição de mãos em fotografia que manuseiam o livro -, Lee nos coloca diante de um Coelho Branco em corpo humano que aplaude ao que estava sendo visto nas páginas anteriores, tudo enquadrado como uma tela de arte na parede.

A inserção de elementos que narram uma história dentro de imagens pode ser vista já nas do palco, cujas cortinas se encontram fechadas, o que contextualiza ainda mais seu leitor na ideia de que a narrativa se dará em forma de encenação.

Com relação ao elenco desta encenação, as pessoas pintadas nas telas que Lee selecionou para a justaposição de seu cenário servem como representações dos muitos personagens que Carroll descreve ao longo de seus escritos. São esses mesmos personagens que, na obra de Carroll, separam Alice do Coelho Branco. Na obra de Lee, podemos ver esta informação traduzida em imagens sobrepostas, de fotografias a ilustrações.

O livro-imagem de Suzy Lee não apenas segue a ideia de tradução intersemiótica cunhada por Roman Jakobson, a partir de um signo verbal, como nos coloca em um outro ambiente de reflexão. Aqui nos referimos ao contexto das adaptações, que não deixam de ser traduções, transcriações, que se utilizam de múltiplos meios para estruturar uma narrativa.

Figura 3 - Alice \& Coelho Branco agradecem e se distanciam do leitor

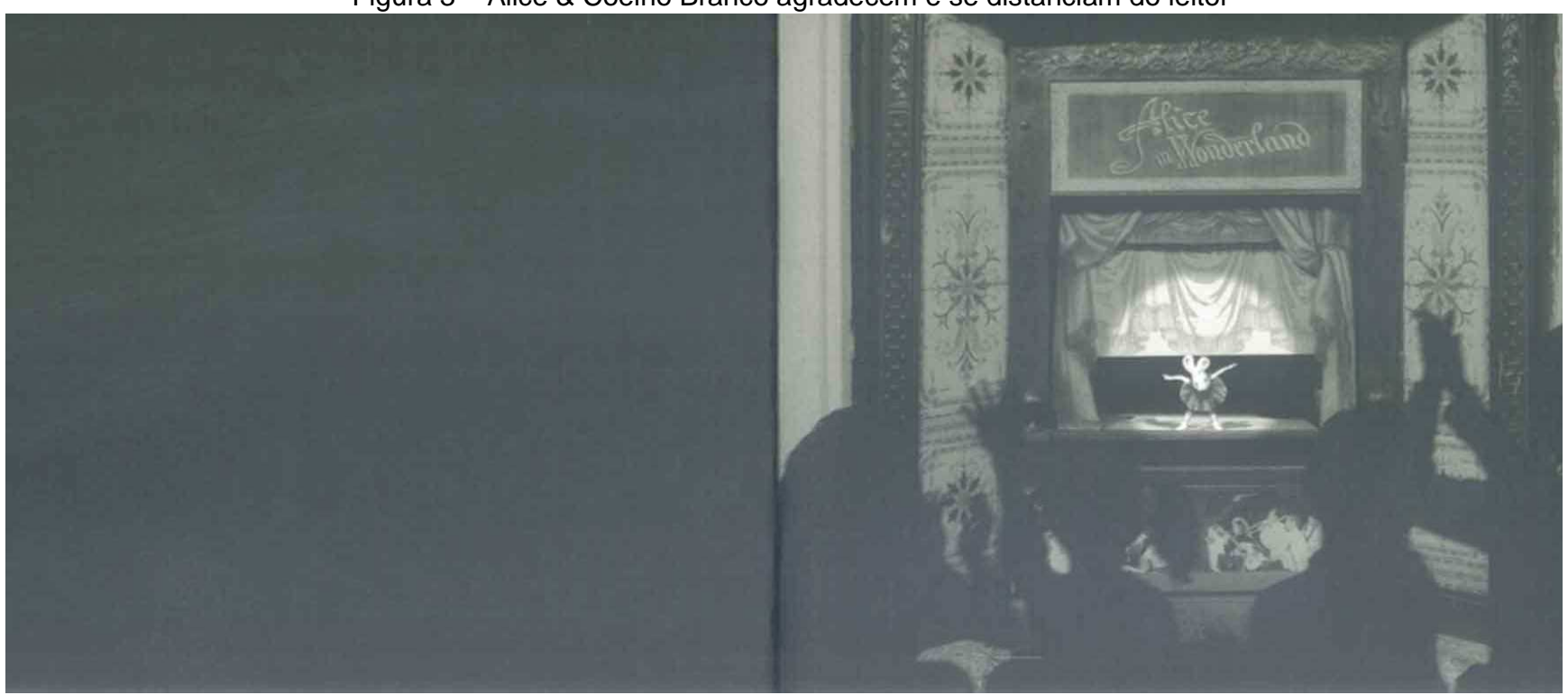

Fonte: Página dupla reproduzida de Lee (2002) primeiras páginas duplas do livro-imagem. Podemos ver a silhueta de uma personagem adulta e duas crianças se preparando para assistir à peça que está prestes a começar. Lee utiliza recortes de fotografias que representam uma orquestra, posicionada à frente

\section{Adaptação literária}

Na área da Literatura Comparada, abrangendo seus desdobramentos e possibilidades, um campo que se destaca nas discussões sobre a tradução literária é 
o das adaptações fílmicas. O entendimento dessas adaptações parte do princípio de Jakobson, segundo o qual uma nova obra será transcriada a partir de uma obra original - produzida em signos verbais -, resultando em uma mescla de signos visuais, sonoros e, também, verbais: o audiovisual.

Nesse contexto destaca-se Robert Stam. Crítico cultural e teórico cinematográfico, Stam aborda as obras fílmicas a partir de uma visão que as compreenda como traduções intersemióticas de obras literárias. Em um ensaio, no qual aborda a tão discutida questão da fidelidade nas adaptações para o cinema, Stam afirma (2000, p. 62): "A metáfora da adaptação como tradução implica um trabalho cuidadoso baseado em uma transposição intersemiótica, com os inevitáveis ganhos e perdas típícos de qualquer tradução"2.

Partindo de reflexões sobre a intertextualidade, termo cunhado pela filósofa e crítica literária búlgara Julia Kristeva (na esteira de Bakhtin), Stam declara (2000, p. 66): "Adaptações fílmicas [...] são apanhadas por um turbilhão de referências intertextuais e transformacionais" - aqui fazemos uma aproximação com o pensamento sobre as transformações da forma, de Julio Plaza - "de textos que geram outros textos em um processo interminável de reciclagem, transformação e transmutação, sem qualquer ponto certo de origem" ${ }^{3}$. Nas adaptações, o texto de chegada é a leitura que o tradutor, adaptador tem do texto de partida. Esse texto é transformado, transmutado segundo referências intrínsecas ao transcriador e à linguagem para a qual se traduz.

Em adição, ao sugerir uma gramática da transformação, Stam escreve (2000, p. 68-9):

O texto original forma uma densa rede informacional, uma série de pistas verbais das quais o texto do filme adaptado pode se apropriar, amplificar, subverter ou transformar. A adaptação fílmica de um romance realiza estas transformações de acordo com o protocolo de uma mídia distinta, absorvendo e alterando os gêneros e intertextos disponíveis

\footnotetext{
2 Tradução nossa para: "The trope of adaptation as translation suggests a principled effort of inter-semiotic transposition, with the inevitable losses and gains typical of any translation".

3 Tradução nossa para: "Film adaptations [...] are caught up in the ongoing whirl of intertextual reference and transformation, of texts generating other texts in an endless process of recycling, transformation, and transmutation, with no clear point of origin".
}

nas entrelinhas de discursos ambientados e ideológicos, além de mediado por uma série de filtros $[\ldots] .^{4}$

Seguindo este pensamento de Stam, sobre uma adaptação poder "se apropriar, amplificar, subverter ou transformar" uma obra original, o pesquisador brasileiro, Marcel Alvaro de Amorim, vem estudando as possibilidades de tais adaptações serem transculturalidades, traduções entre culturas distintas, não apenas entre mídias. Amorim pesquisa as adaptações para o teatro de peças do britânico William Shakespeare e como estas transcriações são apropriadas, amplificadas e transformadas em uma nova obra, que não deixa de ser original, a ser exposta em outro contexto, outra cultura.

Em um de seus artigos, Amorim (2013) faz um levantamento breve do estado da arte em torno desta discussão, expondo também sua pesquisa no que se refere à tradução entre culturas - de um contexto cultural de partida para outro, distinto - como uma prática que envolve perdas e ganhos, e que se resignifica a partir de seu contexto de chegada. Em seus escritos, o pesquisador expõe que

[...] a adaptação enquanto prática antropofágica pode, em analogia com as palavras de Haroldo Campos (Metalinguagem e outras metas, [2013]) - a partir de sua ideia de uma tradução antropofágica - transcriar, criar o texto novamente - ou paralelamente -, adaptando não apenas o significado, mas também a própria materialidade do literário, suas propriedades, sua narrativa, sua cultura de partida etc. (AMORIM, 2013, p. 30-1)

Sabendo que o termo transcriação, tão utilizado por Haroldo de Campos em suas discussões sobre a tradução literária, é chave para as reflexões sobre adaptação fílmica, sugerimos outra leitura. Para continuar a reflexão aqui proposta, tomamos emprestado o termo "adaptação fílmica" e o utilizaremos como "adaptação literária" para nos referirmos às criações feitas por Suzy Lee a partir de

\footnotetext{
4 Tradução nossa para: "The source text forms a dense informational network, a series of verbal cues that the adapting film text can then take up, amplify, ignore, subvert, or transform. The film adaptation of a novel performs these transformations according to the protocols of a distinct medium, absorbing and altering the genres and inter texts available through the grids of ambient discourses and ideologies, and as mediated by a series of filters $[\ldots] "$.
} 
Lewis Carroll, ação esta que distingue a obra Alice in Wonderland publicada em livro ilustrado da sua adaptação em livro-imagem.

\subsection{Carroll por Lee}

Quando afirmamos anteriormente que Suzy Lee transcria a narrativa original de Lewis Carroll até determinado ponto da história, referíamo-nos à página dupla na qual Alice está quase agarrando o Coelho Branco - após páginas de imagens sequenciais referentes à tão conhecida perseguição. O Coelho Branco, que era uma ilustração de carvão em papel branco e que vinha diminuindo de tamanho à medida que Alice se aproximava, em um virar de página, tornase uma fotografia de uma cabeça de algodão e olhos aterrorizantes de coelho com um manto em tecido cobrindo seu corpo (Figura 4). E aqui começa a adaptação inédita de Alice por Lee.

A partir daí, é o Coelho Branco quem persegue Alice, que corre amedrontada daquele que, até então, ela vinha perseguindo. Tal história não se encontra na
Enquanto o Coelho Branco se aproxima, Alice vai diminuindo de tamanho, um jogo de opostos presente na história de Carroll e condizente com o que Stam aponta quanto às "pistas verbais" que serão pontos de partida para uma adaptação. No entanto, quando o Coelho Branco alcança Alice, as luzes no palco ficcional se apagam, cria-se um suspense. Quando as luzes voltam a acender, os personagens se transfiguraram, deixando-nos diante de uma figura inédita: o corpo de menina em fotografia com a cabeça em algodão de um coelho.

Quando se faz uma leitura dos códigos verbais criados por Carroll em 1865, podemos visualizar claramente o papel de contraponto dado ao Coelho Branco em relação à protagonista da narrativa, uma vez que ele é o estimulador do percurso que Alice faz pelo País das Maravilhas. Logo, se encararmos o comportamento espelhado do Coelho Branco à perseguição inicial de Alice, podemos também sugerir que Suzy Lee adaptou, em seu livro-imagem, a ideia

Figura 4 - Alice e o Coelho invertem de papéis na perseguição

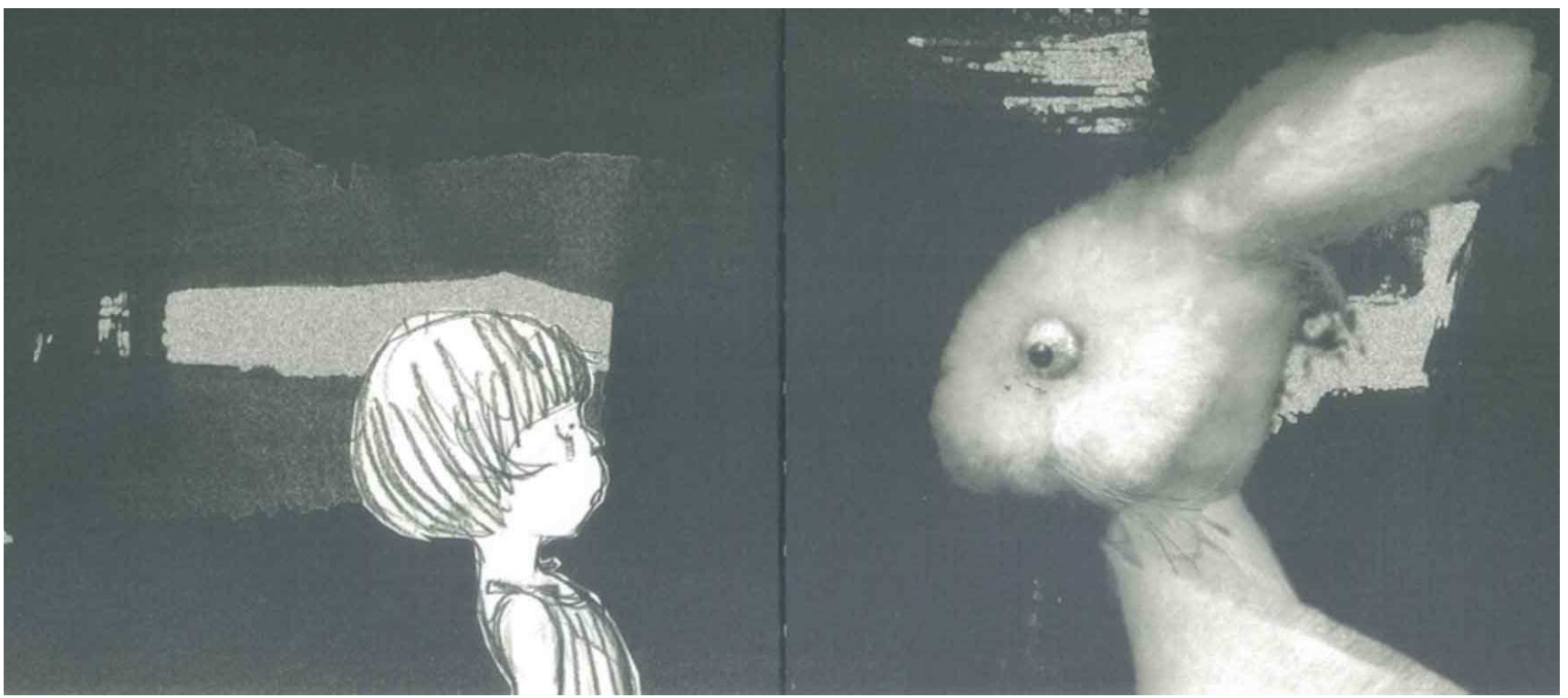

Fonte: Páqina dupla reproduzida de Lee (2002) obra de Carroll, tornando assim a adaptação de Lee uma obra original, porém sem deixar de ser uma tradução, uma transcriação, uma vez que até mesmo a materialidade do livro é adaptada - aqui em harmonia com o pensamento de Amorim sobre adaptação como tradução antropofágica. principal presente em Through the Looking-Glass, de Carroll.

Ao se utilizar de procedimentos como o zoom in, no início da narrativa, que vai aproximando o leitor do palco onde será encenada a história; a invasão e posterior utilização da página dupla para contextualizar 
o mundo ficcional imaginário, onde Alice e o Coelho Branco realizam uma perseguição mútua nos bastidores do cenário principal; o zoom out, no final da narrativa, que vai afastando o leitor do palco, expondo uma das personagens que estava assistindo à peça, e depois o Coelho Branco que estava apreciando tudo isso, Suzy Lee transforma em cenas, quase que numa animação, a história criada por Lewis Carroll. As perdas em relação ao texto de partida estão em equilíbrio com os ganhos no texto de chegada.

Podemos apontar ainda, dentro da ideia de adaptação literária, os usos que Lee faz das ilustrações criadas por Sir John Tenniel para o livro de Carroll. Os gêmeos Tweedledee e Tweedledum, que, enquanto signos verbais, exercem papel de espelhos de uma mesma persona na imaginação de Alice, aparecem na obra de Lee como recortes em páginas opostas quando os signos visuais ocupam toda a página dupla (Figura 5). E eles voltam a aparecer quando a peça já se encontra findada, como na transfiguração vivida pela personagem que antes estava assistindo à peça no palco da lareira. A personagem feminina que encera o chão, em fotografia, aparece duplicada em uma versão com cabeça de coelho dentro da própria lareira.

Além disso, sabemos que a protagonista de Carroll foi ilustrada como uma garotinha de cabelos louros e com vestido aristocrático - uma tradução em imagem por Sir John Tenniel para um contexto europeu no final do século XIX -, porém a versão de Alice que Lee nos traz é mais uma de suas adaptações. Podemos dizer, na esteira do que diz Amorim sobre a tradução entre culturas, que a protagonista do livro-imagem de Lee foi transcriada em um contexto cultural distinto do seu texto de partida.

Assim como informado anteriormente, Alice in Wonderland foi escrito a pedidos de uma garotinha chamada Alice Liddell, que fora fonte de inspiração para a narrativa de Carroll. Assim sendo, Suzy Lee poderia também ter se apropriado desta ideia, uma vez que sua Alice e a garotinha Liddell se assemelham fisicamente (Figura 6). No

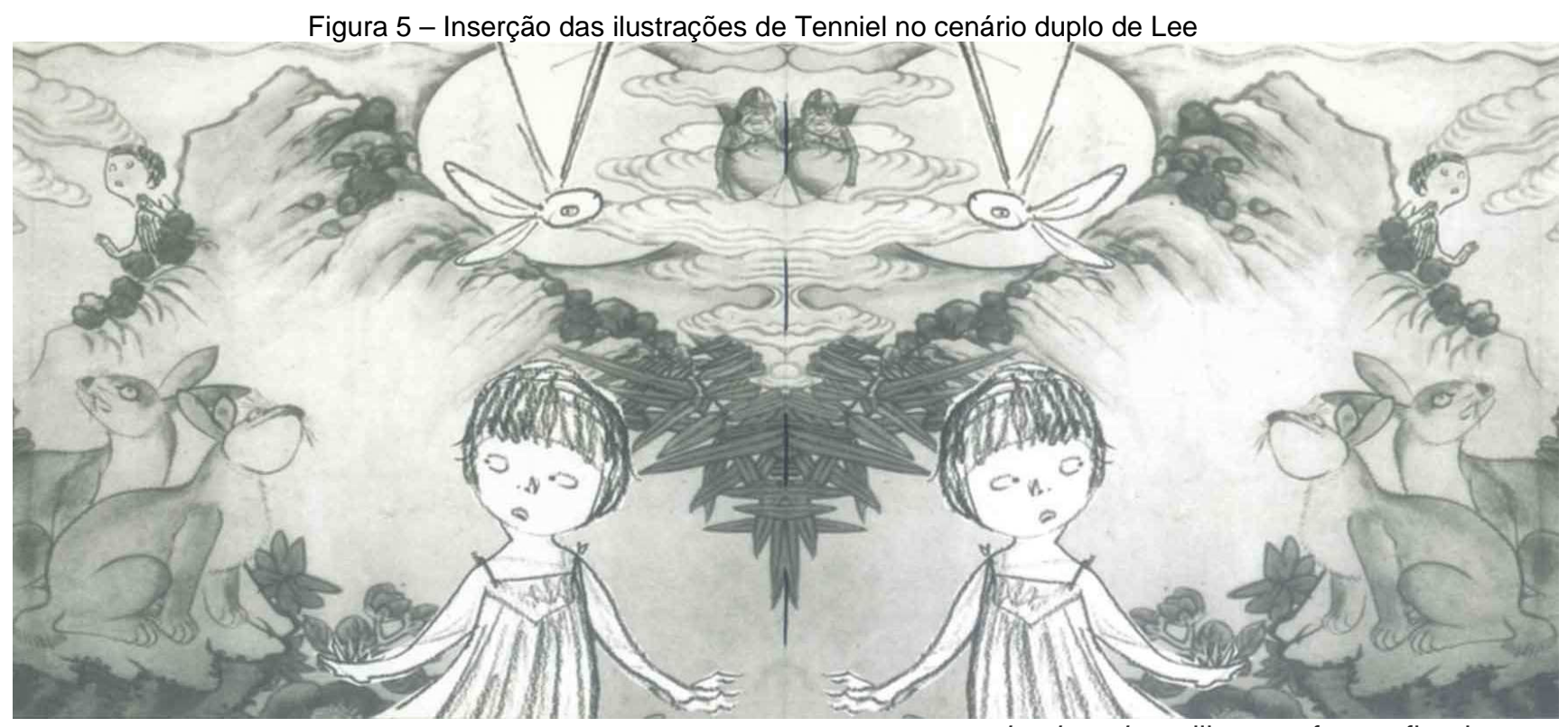

Fonte: Página dupla reproduzida de Lee (2002) recortes duplos em cada lado da lareira que serviu de palco para a encenação. Ainda nessa página, podemos ver recortes de outras ilustrações feitas por Tenniel, como o Chapeleiro Maluco e a própria Alice.

A adaptação de Lee para a ideia de duplo não se encerra apenas em Alice e Coelho Branco, ou em Tweedledee e Tweedledum, como também se mostra entanto, a book artist utilizou a fotografia de uma garotinha oriental, elemento que contextualiza sua cultura, originalmente oriental, sul-coreana.

Todos os elementos que Lee faz uso na produção de sua narrativa sem palavras estão diretamente relacionados com as ideias presentes na obra de Carroll. O espaço fronteiriço desta tradução em imagens é o mesmo no qual nos vemos suspensos 
ao longo da leitura do livro em signos verbais, mesmo limiar que nos deixa em dúvida se estamos sonhando ou acordados, se estamos diante ou dentro do espelho, se estamos folheando ou imersos no livro.

Em sintonia com o pensamento de Stam, este "processo interminável de reciclagem" da narrativa de Carroll, adaptada por Lee, cria novas possibilidades de leitura, novos contextos para esta que é uma das mais clássicas obras da literatura infantil e juvenil e da literatura universal.

\section{Considerações finais}

Apesar de Alice ser uma das personagens literárias que habita o imaginário de muitos leitores a traz à tona o potencial literário que os livros-imagem possuem dentro de suas limitações, dadas pelo próprio objeto livro. As narrativas feitas sem palavras, só com imagens, oferecem inúmeras novas leituras - inclusive a leitura de uma obra completamente diferente daquela escrita em Londres no final do século XIX.

A tradução intersemiótica de Alice publicada no início do século $\mathrm{XXI}$, em sintonia com o pensamento de Jakobson, mostra que as possibilidades de resignificação, partindo de signos verbais ou visuais ou sonoros, dependem sempre dos referenciais de cada leitor, tradutor. $O$ intercurso de sentidos, que gera novos signos para os textos de partida, é fonte inesgotável de transcriações, de inéditos textos de chegada.

Figura 6 - Alice Liddell, à esquerda, e a Alice de Lee, à direita

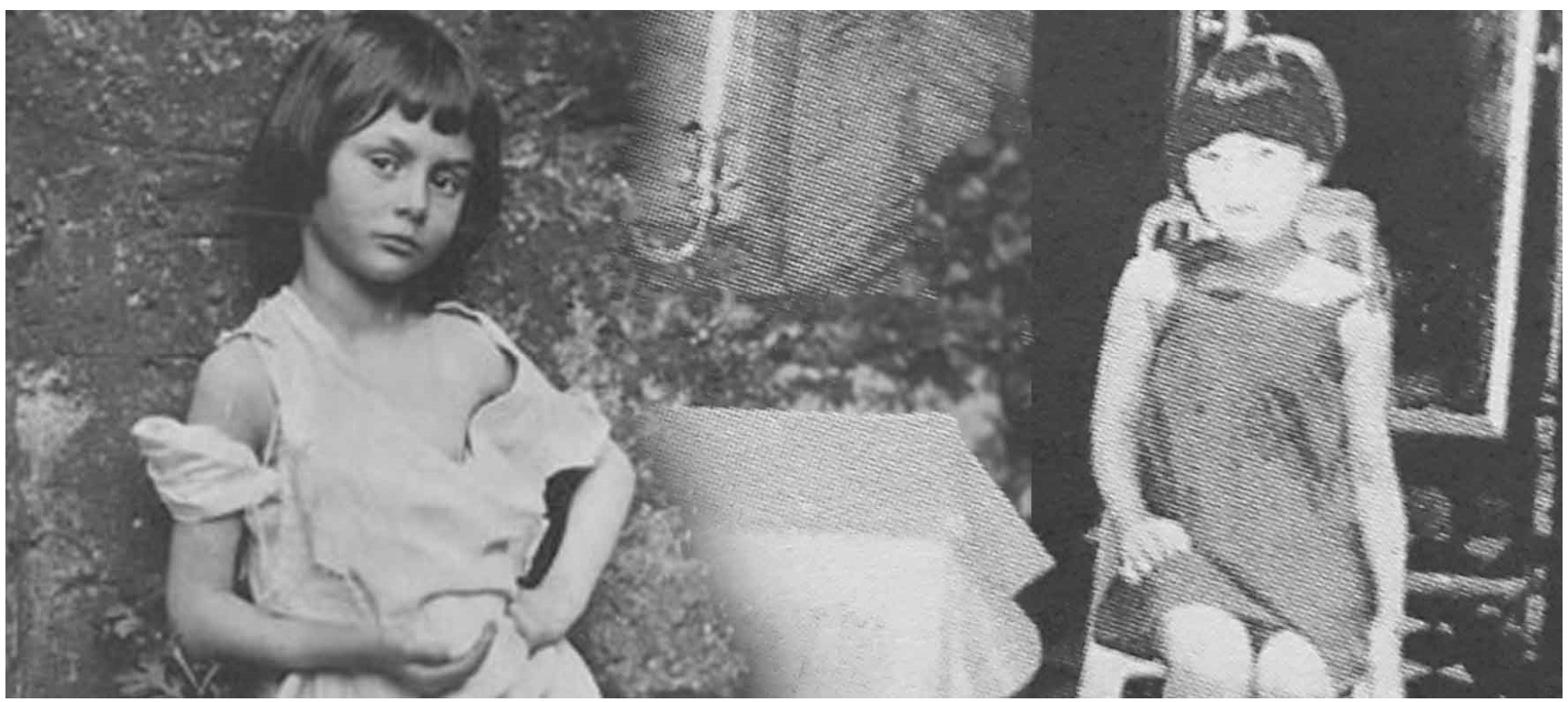

Fonte: Recortes mesclados a partir das obras de Carroll (2015) e de Lee (2002)

partir de suas representações, como as ilustrações de Sir John Tenniel, ou pela animação da Disney, ou mesmo pelo live action dirigido por Tim Burton, não podemos esquecer que tais representações não passam de leituras, traduções, recriações feitas em mídias distintas a partir dos signos verbais impressos em páginas por Lewis Carroll há 150 anos, resultado de uma narrativa oral que ele próprio fez para uma garotinha chamada Alice.

Esta possibilidade de transcriação, adaptação que Suzy Lee nos apresenta, em imagens sequenciais,
Vale ressaltar ainda que, apesar de produzido em Londres, onde a obra de Lewis Carroll foi escrita, o livro-imagem de Suzy Lee se encontra em um outro contexto britânico, transformado pelo olhar da book artist e influenciado por outras culturas - como a da própria artista sul-coreana. A arte da recriação literária dispõe das mais distintas facetas, dependendo apenas de como a mensagem, a função poética da linguagem, é recebida por aquele que realizará uma tradução.

Assim como, no final do século XIX, os livros ilustrados ganharam espaço no mercado literário 
destinado às crianças e jovens, onde muitas ilustrações complementavam narrativas criadas em signos verbais, os livros-imagem, na contemporaneidade, possibilitam uma liberdade dos signos visuais com relação aos signos verbais. As imagens poéticas das narrativas sem palavras propõem uma leitura visual, com base no imaginário do leitor.

Somente ao finalizar seu livro-imagem, inspirada pela obra de Lewis Carroll, Suzy Lee utiliza signos verbais extraídos diretamente do livro ilustrado do autor britânico, impressos no virar da última página, onde se lê: "A vida o que é, senão sonho?"5

\section{Referências}

AMORIM, Marcel A. Da tradução intersemiótica à teoria da adaptação intercultural: estado da arte e perspectivas futuras. Itinerários, Araraquara, n. 36, p. 15-33, jan./jun. 2013.

CAMPOS, Haroldo. Metalinguagem \& outras metas: ensaios de teoria e crítica literária. 4a ed. São Paulo: Perspectiva, 2013.

CARROLL, Lewis. Alice através do espelho e o que ela encontrou lá. São Paulo: Cosac Naify, 2015. 208 p.

DÄLLENBACH, Lucien. El relato especular. Madri: Visor, 1991. $226 \mathrm{p}$.

JAKOBSON, Roman. Lingüística e comunicação. 6 $6^{\text {a }}$ ed. São Paulo: Cultrix, 1974. 162 p.

LEE, Suzy. Alice in Wonderland. Mantua: Corraini Edizioni, 2002. 32 p.

A Trilogia da Margem: o livro-imagem segundo Suzy Lee. São Paulo: Cosac Naify, 2012. $192 \mathrm{p}$.

PLAZA, Julio. Tradução Intersemiótica. São Paulo: Perspectiva, 2003. 232 p.

STAM, Robert. Beyond fidelity: the dialogics of adaptation. In: NAREMORE, James (Org.). Film Adaptation. New Jersey: Rutgers University Press, 2000. 272 p. p. 54-76.

\section{COMO CITAR ESSE ARTIGO}

GIRÃO, Luis Carlos; CARDOSO, Elizabeth da Penha. Alice in Wonderland: uma tradução literária em imagens por Suzy Lee. Signo, Santa Cruz do Sul, v. 41, n. 72, out. 2016. ISSN 1982-2014. Disponível em: $<$ https://online.unisc.br/seer/index.php/signo/article/view/7160>. Acesso em: doi: http: //dx.doi.org/10.17058/signo.v41i72.7160.

\footnotetext{
${ }^{5}$ Tradução nossa para: "Is all our life, then, but a dream?"
} 